\title{
Arm ache
}

\section{Hosein Ahmadzadeh Chabok • David Ring}

Published online: 19 February 2014

(C) American Association for Hand Surgery 2014

\begin{abstract}
Both patients and providers hope for better management strategies for nonspecific activity-related upper limb pain (herein referred to as "arm ache"). The next innovation in the care of arm ache may arise from the strong evidence that mood, coping strategies (e.g., catastrophic thinking), and heightened illness concern - all very responsive to treatment with cognitive behavioral therapy - account for a large percentage of the variation in symptom intensity and magnitude of disability. This focus on treatments to reduce symptoms and disability represents a change in culture for patients and providers, both of whom are accustomed to the biomedical framework that anticipates a direct correspondence between illness (the state of being unwell) and disease (pathophysiology). Not all patients are ready for such an approach, but as a first step health providers can prioritize empathy; remain mindful that words, illness concepts, and treatments can reinforce ineffective coping strategies; and encourage curiosity about the human illness experience.
\end{abstract}

Keywords Coping strategy · Biopsychosocial framework · Biomedical framework - Arm pain - Cognitive therapy · Rational therapy

\footnotetext{
H. A. Chabok

Surgery Department, Shamsoshomoos Hospital, Malekoshoara

Bahar54, Shariati Square, Mashhad, Khorasan Razavi, Iran

e-mail: h.ahmadzadeh.c@gmail.com

D. Ring $(\bowtie)$

Department of Hand Surgery, Massachusetts General Hospital, Yawkey 2100, 55 Fruit St., Boston, MA 02114, USA

e-mail: dring@partners.org
}

\section{Introduction}

Nonspecific activity-related arm pain is common. It can be associated with vocational, scholarly, or avocational (e.g., music/exercise) activities. Repetitive strain injury may be the modern version of what was once known in North America as "writer's cramp" [25]. For more than a century, nonspecific activity-related arm pains were ascribed to new technologies [25]. Such illness constructions have several shortcomings: (1) they imply an objective impairment or pathophysiology where none can be identified, (2) they stigmatize and demonize hand use, (3) they provide no benefit in treatment and may distract patients and providers from effective treatments such as cognitive behavioral therapy, and (4) there is compelling evidence - most recently from the Australian epidemic - that these illness constructions actually increase illness behavior $[22,25]$. Stated more directly, there is compelling evidence that health providers have mismanaged nonspecific activityrelated arm pains in a way that actually increases illness both in specific patients and in populations in general.

We might one day identify not only the underlying pathophysiology, but also potential disease-modifying treatments for arm pains that currently puzzle us. But given the frustrations associated with headaches and backaches in spite of years of research, management strategies in the absence of disease-modifying treatment are important. A detailed examination of this process suggests that there are effective methods to help patients with nonspecific activity-related arm pains that are underappreciated and underutilized.

\section{The Australian RSI Epidemic}

In Australia in 1983, an illness characterized by activityrelated pain without any objective pathophysiology or impairment was labeled "repetitive strain injury" (RSI) and 
promoted $[22,25,50]$. An analysis of the resulting epidemic of disabling nonspecific arm pain suggests that it was a psychosocial phenomenon $[4,19,22,25,50]$. In other words, a well-intentioned illness construction led to a widespread of illness similar to what is observed in outbreaks of conversion disorder [4, 19, 50].

A key incentive for growth of the epidemic was claims for compensation. But the court reviewed the evidence and concluded that repetitive strain injury is a misnomer because there is no evidence of injury $[4,19,22,25,41,50]$.

Psychologists describe the normal human protective response to pain as catastrophic thinking. We prepare for the worst, and sometimes we take it too far and become more symptomatic and disabled than we deserve. The Australian epidemic of "RSI" reminds us that humans in pain are vulnerable. Such medical missteps teach us that the creation of an illness construction that stigmatizes and demonizes hand use while implying that there is some progressive objective impairment or pathophysiology contributes to more symptoms and disability. If we are honest with ourselves, the Australian epidemic of RSI is a sobering example of man-made illness, the power of psychological and sociological influences, and the need for caution, compassion, curiosity, and humility among health providers $[4,19,22,25,41,50]$.

\section{Science}

Medicine is a science-based profession, but science as curiosity or applied skepticism needs emphasis. In the modern world, things are often explained in scientific terms without having good evidence from experiments designed to account for human adeptness at pattern formation and rationalization. Such pseudoscience lacks basic elements of science such as falsifiability/verifiability, reproducible objective measurements, and clear definitions [35].

Pseudoscience is a trap for all humans, including medical authorities. Man-made diagnoses are often presented side by side with truly scientific concepts in medical education. The appeal of pseudoscientific diagnoses and illness constructions can be explained in part by the fact that humans prefer to have a name for their problem. A specific diagnosis can relieve any suspicion of malingering and allows the patient to join a community of sufferers. On the other hand, diagnoses can lead to misuse of resources and iatrogenic harm. In particular, a biomedical label (e.g., "fibromyalgia") might distract patients from the psychosocial and psychological aspects of their illness and arguably from the most effective treatment strategies $[5,9,12-16,37]$.

Some hand surgeons diagnose electrophysiologically normal carpal tunnel syndrome or "atypical carpal tunnel syndrome" (ACTS) based more on diffuse and disabling pain than on the numbness more typical of carpal tunnel syndrome.
There is an attempt at scientific verification of this diagnosis in experiments that measure serum neuropeptide [2]. Other debatable diagnoses in hand surgery include most diagnoses of thoracic outlet syndrome, pronator syndrome, radial tunnel syndrome, and pre-dynamic scapholunate instability. The common thread is disabling symptoms with no objectively verifiable pathophysiology. Hand surgeon diagnoses can lead to surgery. When psychologists and psychiatrists treat illnesses with substantial symptoms and disability but no objective pathophysiology, they manage them as somatoform disorders. Techniques such as cognitive behavioral therapy are measurably effective. Surgery for hand and upper extremity illnesses characterized by substantial symptoms and disability with no measureable impairment or pathophysiology may not only be unnecessary and potentially harmful (benefitting only from the placebo effect), but it may also distract the patient from effective treatment with cognitive behavioral therapy.

\section{Psychology}

The normal functioning of the human mind is prone to errors. In particular, we take shortcuts to things that are familiar, we try to limit effort in rethinking our interpretations, and we tend to prepare for the worst in response to noxious stimuli. Rational thought and science are tools that humans have developed to keep these intuitive, "first line" thoughts and emotions in check. Cognitive behavioral therapies and behavioral exercises help humans develop their rational control of gut feelings. There is strong evidence that these programs decrease symptoms and disability (they increase health and wellness), independent of the type and degree of pathophysiology present.

The evidence is strong that psychological and personality factors are as important as or even more important than the pathological process in the experience of pain, especially when the source of nociception is vague or uncertain. Patients with idiopathic arm pain often report more extreme pain and experience more anxiety than patients with arm pain with an identifiable source [32, 34].

Nonspecific arm pain may be a somatic presentation of psychological distress or a representative of a heightened sensitivity to bodily sensations. Lower mood and ineffective coping strategies are major factors [32, 34].

Patients with nonspecific arm pain exhibit high levels of catastrophic thinking in response to pain and show a tendency for increased somatic complaints [32, 34]. The opposite of catastrophic thinking is self-efficacy - a sense of control and confidence that things will turn out satisfactorily. Patients with lower self-efficacy/greater catastrophic thinking experience higher pain intensities [28, 48, 51]. A somatoform disorder is diagnosed when disabling symptoms cannot be attributed to an objectively verifiable disease [46]. Patients with increased 
concerns about their health interpret benign symptoms as indicative of serious illness [45]. Psychosomatic complaints seem to have gradually moved away from objectively verifiable complaints (e.g., paralysis) to subjective symptoms that cannot be objectively proved or disproved such as pain and fatigue [1].

Psychosocial stressors in the workplace appear to play an important role in disabling nonspecific pains $[6,26,30,31$, $38,49]$. Workers experiencing a combination of physical and psychological stress are more likely to report arm pain $[6,38]$.

One of the strongest risk factors is dissatisfaction with support from colleagues or supervisors [26]. Working situations characterized by high psychological demands, low decision latitude, and low social support play an important role in perception of pain in the upper limb, especially in women, and it seems that there is a synergetic relationship between mechanical exposure and job strain $[6,30,38]$.

\section{A New Approach}

Illness is the state of being unwell. Humans can be ill without having disease (pathophysiology) [44, 49]. Consequently, the biomedical framework - which expects a strict correlation between nociception (actual or potential tissue damage) and pain (discomfort) - is inadequate. A biopsychosocial framework that takes advantage of the opportunities based on how humans interpret and respond to symptoms seems more appropriate and helpful [44].

Every patient with upper extremity pain should be evaluated and monitored to be sure that treatable pathology is not overlooked. Patients without identifiable pathophysiology are diagnosed accurately, neutrally, and descriptively as "nonspecific upper extremity pain." This is essentially "arm ache." Just like headache or backache, arm ache is common, annoying, and frustrating but has no identifiable or worrisome pathophysiology. Pathophysiological terms such as "tendonitis" or "atypical carpal tunnel syndrome" should be avoided when they are speculative and debatable. The term "workrelated upper extremity disorder," although descriptive, is unhelpful because it stigmatizes work and implies a causal relationship. Arm ache is preferable.

Indiscriminate use of diagnostic tests in the setting of arm ache (vague diffuse idiopathic upper extremity pain) is unlikely to yield useful information and may lead to overinterpretation of age-related changes or expected variations. This might lead to unnecessary treatments. Time is often the best diagnostic test [33, 44].

Nonspecific illnesses are treated nonspecifically (e.g., ice/ heat, acetaminophen/NSAIDs, splints, stretching/ conditioning, etc.) $[11,20,29]$. Following the lessons learned in the management of low back pain, in the absence of pathophysiology requiring restriction of activity (e.g., a healing fracture), activity is not restricted [17, 47]. Continuing with a normal routine is an important part of recovery, and pain avoidant behavior is part of the illness [3, 17, 44, 47].

The role of ergonomic interventions is debatable. They might be useful for optimizing comfort, but promotion of a "correct" way to do things creates a corresponding "incorrect" way that is counterproductive in the context of an illness strongly influenced by catastrophic thinking and heightened illness concern. There is evidence that ergonomic interventions have done little to reduce workplace complaints [8, 27, 30, 43].

Self-efficacy (the belief in success based on one's own initiative; "I can do it...everything will be fine") is a cognitive factor associated with fewer symptoms and less disability. Patients with high levels of self-efficacy choose active coping strategies such as distraction (mental focus on something other than that the problem), reinterpreting pain sensations, and positive coping statements. Self-efficacy can be learned, practiced, and grown [10, 18, 36, 42, 44].

Psychological interventions such as cognitive behavioral therapy and biofeedback are effective in growing self-efficacy. Cognitive behavioral therapy forms an important part of an interdisciplinary approach to arm ache [7, 21, 23, 24, 39, 40, 44].

\section{Conclusion}

The treatment of arm ache can be frustrating. Physicians can contribute to symptoms and disability with inappropriate reactions (such as ordering too many tests, applying inappropriately specific or stigmatizing diagnoses, and recommending potentially unnecessary treatments) that unintentionally encourage illness behaviors. An honest explanation of the uncertainties and an empathetic acknowledgement of psychological and sociological factors may help the patient seek help developing effective strategies for managing symptoms.

Conflict of Interest Hosein Ahmadzadeh Chabok has no conflict of interest related to the content of this review.

David Ring has no conflict of interest related to the content of this review.

Statement of Human and Animal Rights This article does not contain any original research on human or animal subjects.

Statement of Informed Consent This article does not contain any original research on human or animal subjects, so informed consent is not an issue.

\section{References}

1. Alpar EK, Killampalli VV, La Ban MM, Riutta JC, Ring D. Idiopathic arm pain/D. Ring replies. J Bone Joint Surg Am. 2005;87(3):677-9. 
2. Alpar EK, Onuoha G, Killampalli VV, Waters R. Management of chronic pain in whiplash injury. J Bone Joint Surg [Br]. 2002;84(6): 807-11.

3. Bach SM, Holten KB. Guideline update: what's the best approach to acute low pain? J Fam Pract. 2009;58(12):E1.

4. Bammer G, Martin B. The arguments about RSI: an examination. Community Health Stud. 1988;12(3):348-58.

5. Bells DS. Epidemic occupational pseudo illness: the plague of acronyms. Curr Rev Pain. 2000;4:324-30.

6. Buckle P. Upper limb disorders and work: the importance of physical and psychosocial factors. J Psychosom Res. 1997;43(1):17-25.

7. Castro MM, Daltro C, Kraychete DC, Lopes J. The cognitive behavioral therapy causes an improvement in quality of life in patients with chronic musculoskeletal pain. Arq Neuropsiquiatr. 2012;70(11):8648.

8. Cook TM, Ludewig PM, Rosecrance JC, Zimmermann CL, Gerleman DG. Electromyographic effects of ergonomic modifications in selected meatpacking tasks. Appl Ergon. 1999;30: 229-33.

9. Engel GL. The need for a new medical model: a challenge for biomedicine. In: Caplan AL, Mc Cartney JJ, Sisti DA, editors. Health, disease, and illness; concepts in medicine. Washington D.C: Georgetown University Press; 2004. p. 51-64.

10. Esteve R, Ramirez-Maestre C, Lopez-Marinez AE. Adjustment to chronic pain: the role of pain acceptance, coping strategies, and pain related cognitions. Ann Behav Med. 2007;33(2):17988

11. Feuerstein M, Callan-Harris S, Hickey P, Dyer D, Armbruster W, Carosella AM. Multidisciplinary rehabilitation of chronic workrelated upper extremity disorders. Long-term effects. J Occup Med. 1993;35(4):396-403.

12. Glass JM. Review of cognitive dysfunction in fibromyalgia: a convergence on working memory and attentional control impairments. Rheum Dis Clin North Am. 2009;35(2):299-311.

13. Goldenberg DL, Burckhardt C, Crofford L. Management of fibromyalgia syndrome. JAMA. 2004;292:2388-95.

14. Gordon DA. Fibromyalgia - real or imagined? J Reumatol. 2003;30: 1665 .

15. Gracely RH, Petzke F, Wolf JM, Clauw DJ. Functional magnetic resonance imaging evidence of augmented pain processing in fibromyalgia. Arthritis Rheum. 2002;46:1333-43.

16. Hadler NM. "Fibromyalgia" and the medicalization of misery. J Rheumatol. 2003;30:1668-70.

17. Hagen KB, Jamtvedt G, Hilde G, Winnem MF. The updated Cochrane review of bed rest for low back pain and sciatica. Spine. 2005;30(5):542-6.

18. Haythornthwaite JA, Menefee LA, Heinberg LI, Clark MR. Pain coping strategies predict perceived control over pain. Pain. 1998;77(1):33-9.

19. Helliwell PS. Diagnostic criteria for work-related upper limb disorders. Br J Rheumatol. 1996;35(12):1195-6.

20. Himmelstein JS, Feuerstein M, Stanek 3rd EJ, Koyamatsu K, Pransky GS, Morgan W, et al. Work-related upper extremity disorders and work disability. Clinical and psychosocial presentation. J Occup Environ Med. 1995;37(11):1278-88.

21. Hoffman BM, Papas RK, Chatkoff DK, Kerns RD. Meta-analysis of psychological interventions for chronic back pain. Health Psychol. 2007;26(1):1-9.

22. Ireland DC. Psychological and physical aspects of occupational arm pain. J Hand Surg (Br). 1988;13(1):5-10.

23. Lawson K, Reesor KA, Keefe FJ, Turner JA. Dimensions of painrelated cognitive coping: cross-validation of the factor structure of the Coping Strategy Questionnaire. Pain. 1990;43:195-204.

24. Linton SJ, Andersson T. Can chronic disability be prevented? A randomized trial of a cognitive-behavior intervention and two forms of information for patients with spinal pain. Spine (Phila Pa 1976). 2000;25(21):2825-31.

25. Lucire Y. Constructing RSI: belief and desire. Sydney: Univ New South Wales; 2003.

26. Macfurlane GJ, Hunt IM, Silman AJ. Role of mechanical and psychosocial factors in the onset of forearm pain: prospective population based study. BMJ. 2000;327(7262):676-9.

27. Maciver H, Smyth G, Bird HA. Occupational disorders: nonspecific forearm pain. Best Pract Res Clin Rheumatol. 2001;21(2):349-65.

28. Michael ES, Burns JW. Catastrophizing and pain sensitivity among chronic pain patients: moderating effects of sensory and affect focus. Ann Behav Med. 2004;27(3):185-94.

29. Miller MH, Topliss DJ. Chronic upper limb pain syndrome (repetitive strain injury) in the Australian workforce: a systematic cross sectional rheumatological study of 229 patients. J Rheumatol. 1998;15(11): $1705-12$.

30. Ostergren PO et al. Incidence of shoulder and neck pain in a working population, effect modification between mechanical and psychosocial exposures at work. Results from a one year follow up of Malmo shoulder and neck study cohort. J Epidemiol Community Health. 2005;59:721-8

31. Reilly PA. "Repetitive strain injury" from Australia to the UK. J Psychosom Res. 1995;39(6):783-8.

32. Rider DA. Psychological factors associated with idiopathic arm pain. J Hand Ther. 2005;18(4):457-8.

33. Ring D, Guss D, Malhotral L, Jupiter JB. Idiopathic arm pain. J Bone Joint Surg Am. 2004;86(7):1387-91.

34. Ring D, Kadzielski J, Malhotra L, Lee SGP, Jupiter JB. Psychological factors associated with idiopathic arm pain. J Bone Joint Surg. 2005;87(2):374-80.

35. Ring D, McCarthy M. Opinion: pseudoscientific explanations of arm pain. J Surg Orthop Adv. 2007;16(3):105-10.

36. Roditi D, Robinson ME, Litwins N. Effects of coping statements on experimental pain in chronic pain patients. J Pain Res. 2009;2:109 16.

37. Short B, Borckardt JJ, George M, Beam W, Reeves ST. Non-invasive brain stimulation approaches to fibromyalgia pain. J Pain Manag. 2009;2:259-76

38. Sim J, Lacey RJ, Lewis M. The impact of workplace risk factors on the occurrence of neck and upper limb pain: a general population study. BMC Public Health. 2006;6:234.

39. Sullivan MJ, Stanish WD. Psychologically based occupational rehabilitation: the Pain-Disability Prevention Program. Clin J Pain. 2003;19(2):97-104.

40. Sveinsdottir V, Eriksen HR, Reme SE. Assessing the role of cognitive behavioral therapy in the management of chronic nonspecific back pain. J Pain Res. 2012;5:371-80.

41. Szbo RM, King KJ. Repetitive stress injury: diagnosis or self fulfilling prophecy? J Bone Joint Surg [AM]. 2000;82:1314-22.

42. Tota-Faucette ME, Gill K, Williams FJ, Goli V. Predictors of response to pain management treatment. The role of family environment and changes in cognitive processes. Clin J Pain. 1993;9:11523.

43. Voerman GE, Vollenbroek-Hutten MMR, Sandsjo L, Kadefors R, Hermens HJ. Prognostic factors for the effects of two interventions for work-related neck-shoulder complaints: myofeedback training and ergonomic counseling. Appl Ergon. 2008;39(6):743-53.

44. Vranceanu AM, Barsky A, Ring D. Psychosocial aspects of disabling musculoskeletal pain. J Bone Joint Surg[AM]. 2009;91:2014-8.

45. Vranceanu AM, Safren S, Cowan J, Ring D. Health concerns and somatic symptoms explain perceived disability and idiopathic hand and arm pain in an orthopedics surgical practice: a path-analysis model. Psychosomatic. 2010;51:330-7. 
46. Vranceanu AM, Safren S, Zhao M, Cowan J, Ring D. Disability and psychologic distress in patients with nonspecific and specific arm pain. Clin Orthop Relat Res. 2008;466:2820-6.

47. Waddell G, Feder G, Lewis M. Systemic reviews of bed rest and advice to stay active for acute low back pain. Br J Gen Pract. 1997;47(423):647-52.

48. Weissman-fogel I, Sprecher E, Pud D. Effects of catastrophizing on pain perception and pain modulation. Exp Brain Res. 2008;186(1): $79-85$.
49. Wikman S, Marklund S, Alexanderson K. Illness, disease, and sickness absence: an empirical test of differences between concepts of ill health. J Epidemiol Community Health. 2005;59:450-4.

50. Winspur I. Arm pain without physical findings: medicine VS the law? J Hand Surg (Br). 2001;26B(5):409-13.

51. Wolff B, Burns JW, Quartana PJ, Lofland K, et al. Pain catastrophizing, physiological indexes, and chronic pain severity: tests of mediation and moderation models. J Behav Med. 2008;31(2):105-14. 